Case Reports in
Gastroenterology
Case Rep Gastroenterol 2020;14:687-694

DOI: 10.1159/000510131

Published online: December 14, 2020 (c) 2020 The Author(s)

Published by S. Karger AG, Basel www.karger.com/crg

This article is licensed under the Creative Commons Attribution-NonCommercial 4.0 International License (CC BY-NC) (http://www.karger.com/Services/OpenAccessLicense). Usage and distribution for commercial purposes requires written permission.

\title{
Paclitaxel-Induced Bowel Perforation: A Rare Cause of Acute Abdomen
}

\author{
Danial Haris Shaikh ${ }^{a, b} \quad$ Ahmed Baiomi ${ }^{a, b} \quad$ Shehriyar Mehershahi ${ }^{a, b}$ \\ Hafsa Abbas ${ }^{a, b}$ Sudharshan Gongati ${ }^{b}$ Suresh Kumar Nayudua, b \\ aDivision of Gastroenterology, BronxCare Hospital Center, a Clinical Affiliate of Mount \\ Sinai Health Systems and Academic Affiliate of Icahn School of Medicine, Bronx, New \\ York, NY, USA; bepartment of Medicine, BronxCare Hospital Center, a Clinical Affiliate of \\ Mount Sinai Health Systems and Academic Affiliate of Icahn School of Medicine, Bronx, \\ New York, NY, USA
}

\section{Keywords}

Neutropenic enterocolitis · Bowel perforation · Acute abdomen · Chemotherapy · Paclitaxel · Abdominal pain

\begin{abstract}
Paclitaxel, a chemotherapeutic agent, is routinely administered for the treatment of various solid organ malignancies. In rare instances, patients receiving infusions of paclitaxel may present with signs of an acute abdomen. Ischemia and necrosis of the bowel wall from chemotherapy-induced neutropenia and direct toxic effects of the drug have been implicated as the cause. We present a case of necrotizing small and large bowel perforation in a patient with breast cancer, 2 weeks after paclitaxel administration.

C) 2020 The Author(s) Published by S. Karger AG, Basel
\end{abstract}

\section{Introduction}

Chemotherapeutic agents are used to treat various malignancies. As these agents do not differentiate between cancer cells and rapidly dividing normal human cells, systemic toxicity is a frequent side effect [1]. A spectrum of gastrointestinal tract adverse events ranging from

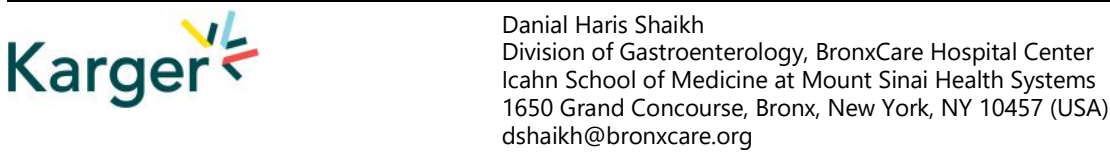




\section{Case Reports in Gastroenterology}

Case Rep Gastroenterol 2020;14:687-694 DOI: 10.1159/000510131

c) 2020 The Author(s). Published by S. Karger AG, Basel www.karger.com/crg

Shaikh et al: Paclitaxel-Induced Bowel Perforation

relatively benign nausea and vomiting to fatal fulminant enterocolitis and intestinal perforation have been reported secondary to chemotherapeutic drugs [2]. Cytotoxic chemotherapeutic agents such as cytosine arabinoside, vinca alkaloids, doxorubicin [3], paclitaxel, docetaxel $[1,4,5]$, 5-fluorouracil, carboplatin, cisplatin [6], gemcitabine, and PEGylated interferon in combination with ribavirin, amongst others, have been implicated in causing gastrointestinal toxicity [7].

Gastrointestinal toxicities due to chemotherapy include secretory/osmotic diarrhea [2, 8], altered intestinal motility [9], gastrointestinal perforation especially with angiogenesis inhibitors [10], direct mucosal cell toxicity with microtubule inhibitors such as taxanes [11], and decreased host defenses such as with immune check point modulators [12]. Neutropenic enterocolitis, ischemic colitis, and Clostridium difficile colitis have all been reported after highdose chemotherapy [13].

Neutropenic or necrotizing enterocolitis (NEC), known as typhlitis when the ileocecal region is involved, is the breakdown of gut mucosal integrity seen in patients with severe myelosuppression, causing transmural inflammation of the colon [14]. It is known to complicate the treatment of various solid and hematological malignancies. Its pathogenesis involves impaired host immune defenses due to neutropenia and/or chemotherapy-induced direct mucosal injury, predisposing the gut to pathogenic organisms [8].

Taxane group chemotherapeutic agents such as paclitaxel and docetaxel are known to cause gastrointestinal toxicity, including NEC. Docetaxel is reported to be the more toxic of the two [1]. Paclitaxel is a plant-based biosynthetic form of taxane that has been used in the treatment of various solid organ malignancies including ovarian, breast, lung, and bladder [11]. Paclitaxel promotes microtubule assembly by enhancing the action of tubulin dimers, stabilizing existing microtubules, and inhibiting their disassembly, thereby interfering with the late $\mathrm{G}_{2}$ mitotic phase of the cell cycle. It distorts mitotic spindles, resulting in the breakage of chromosomes, which prevents the cell from entering into further phases of the cell cycle and finally leads to apoptosis [15]. A few cases of paclitaxel-induced bowel perforation have been reported in the literature [11, 16-19].

We present a case of necrotizing small and large bowel perforation in a patient with breast cancer 2 weeks after paclitaxel administration.

\section{Case Report}

A 79-year-old female with the medical comorbidities of hypertension, diabetes mellitus, asthma, gastroesophageal reflux disease, osteoporosis, and depression was sent to the emergency department from the oncology clinic for the evaluation of fever and hypotension. She had been diagnosed with stage 2, triple-marker (estrogen/progesterone/HER2)-negative, invasive ductal carcinoma of the right breast a year prior to presentation, and had undergone a modified radical mastectomy with lymph node dissection 6 months earlier. Subsequently, she had been receiving adjuvant chemotherapy with a DAC (doxifluridine/Adriamycin/cyclophosphamide) regimen and weekly paclitaxel. She had already completed 11 cycles of the regimen, with her last dose of paclitaxel administered 2 days prior to presentation.

Her cancer treatment course had been complicated by nausea, lethargy, loss of appetite, and intermittent episodes of non-bloody diarrhea. Infectious etiologies such as $C$. difficile had been ruled out, and the diarrhea along with the other symptoms were thought to be secondary to the chemotherapeutic agents. She was taking loperamide and ondansetron in order to

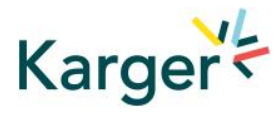




\section{Case Reports in Gastroenterology}

Case Rep Gastroenterol 2020;14:687-694 DOI: $10.1159 / 000510131$

c) 2020 The Author(s). Published by S. Karger AG, Basel www.karger.com/crg

Shaikh et al.: Paclitaxel-Induced Bowel Perforation

control these symptoms. A few months ago, she had also received filgrastim for neutropenia (absolute neutrophil count $1,100 / \mu \mathrm{L}$ ), after which her white cell counts improved and the neutropenia resolved (absolute neutrophil count 6,200/ $\mu \mathrm{L}$ ).

She was a lifelong smoker with a 20-pack-year smoking history and denied any alcohol or illicit substance use. Her family history was remarkable for a daughter with breast cancer, also on treatment. She had undergone a screening colonoscopy 2 years previously, revealing a tubular adenoma and colonic diverticulosis.

On initial evaluation, she was febrile (temperature $100.5^{\circ} \mathrm{F}$ ) and hypotensive (blood pressure 86/55 $\mathrm{mm} \mathrm{Hg}$ ) with sinus tachycardia (heart rate $114 \mathrm{bpm}$ ) and tachypnea (respiratory rate 22 breaths/min), necessitating management with intravenous fluids and broad-spectrum antibiotics (intravenous vancomycin and piperacillin/tazobactam). Her initial physical examination was grossly normal, including normal mentation, a benign abdomen, and clear lungs on auscultation. However, she had noticeable cachexia due to her underlying malignancy.

Her laboratory results revealed anemia (hemoglobin $8.9 \mathrm{~g} / \mathrm{dL}$ ) and neutropenia (absolute neutrophil count $1,300 / \mu \mathrm{L}$ ). She was stabilized and admitted to the oncology unit for further management. She continued to receive chemotherapy as an inpatient, and her initial workup to identify any source of infection, including cultures (blood and urine) and a chest X-ray, was unrevealing. Two days later, the antibiotics were discontinued, and the patient was started on treatment for asthma exacerbation with intravenous steroids. Over the next few days, she remained in a stable condition and her steroids were transitioned to an oral tapered regimen.

On the 12th day of admission, she was transferred to the critical care unit as her general medical condition suddenly deteriorated. She complained of a dry cough and diffuse abdominal pain. On examination, she had a pale complexion and diffuse abdominal tenderness to palpation, with guarding. A stat X-ray of the chest (Fig. 1) was obtained, on which she was noted to have free intraperitoneal air under the right diaphragm. Subsequently, she underwent computed tomography (CT) of the abdomen (Fig. 2), which demonstrated a prominent amount of free intraperitoneal gas with an abnormal right colonic area of ill-defined soft tissue morphology that was opined to be the site of visceral perforation. She was evaluated by the surgical team and underwent emergent exploratory laparotomy.

Intraoperatively, a large perforation in the proximal transverse colon and hepatic flexure, with nonviable tissue in the sigmoid colon, was noted. Other intraoperative findings included multiple areas of patchy necrosis of the small intestine with perforation, and contamination of the abdominal cavity with bile and feces. Her intraoperative course was complicated by profound hypotension (systolic blood pressure $70 \mathrm{~mm} \mathrm{Hg}$ ) and blood loss. She required blood and albumin transfusions, along with vasopressors and fluid support during the surgery. Due to the extent of her disease and hemodynamic instability, resection was not attempted, and eventually the abdominal wound was closed.

Her postoperative course saw a continued state of shock and multiorgan failure requiring vasopressors and mechanical ventilator support. Further resuscitative measures were unsuccessful, eventually leading to the patient's demise less than a day after surgery.

\section{Discussion}

A novel form of paclitaxel, the nanoparticle-albumin bound, is a water-soluble, negatively charged, stable variant that is said to be twice as potent [20]. However, albumin-bound paclitaxel has also been reported to cause gastrointestinal complications, including intestinal

\section{Karger'=}




\section{Case Reports in Gastroenterology}

Case Rep Gastroenterol 2020;14:687-694 DOI: $10.1159 / 000510131$

Shaikh et al.: Paclitaxel-Induced Bowel Perforation

perforation, ischemic colitis, and neutropenic colitis [20]. Common toxicities of paclitaxel therapy include alopecia, neutropenia, hypotension, fever, hepatotoxicity, myalgia, and peripheral neuropathy [21]. NEC leading to bowel perforation as a toxicity has rarely been reported [11, 22-25].

The etiology of NEC can be multifactorial, and includes drugs, infections, intramural hemorrhage, ischemia, and altered immune function. The pathogenesis of chemotherapy-induced NEC involves direct mucosal injury and/or impaired host immune defenses due to neutropenia, predisposing the gut to pathogenic organisms [26]. Conditions impacting the immune system, such as acquired immunodeficiency syndrome (AIDS), myelodysplastic syndromes, solid organ and bone marrow transplantations, solid malignant tumors, and lymphomas, amongst others, can all predispose patients to developing NEC [27, 28]. Signs and symptoms compatible with NEC include abdominal pain, fever, diarrhea, abdominal distension, and blood or mucus in the stool [27].

When secondary to chemotherapy, NEC is said to occur around 2 weeks after initiation [14], corresponding to the neutrophil count nadir. It most commonly occurs in the right colon, although it can manifest anywhere in the small or large bowel. CT scan findings include nonspecific wall thickening, edema, and pericolic fat stranding. Transmural necrosis and perforation are known to occur in severe cases [27]. Various bacterial and/or fungal organisms are often seen infiltrating the bowel wall. Polymicrobial infection is frequent [29].

Structural abnormalities of the bowel, such as diverticulitis, previous surgeries, or infiltrative tumors, heighten the risk of NEC following chemotherapy [14]. Administration of dexamethasone after paclitaxel therapy [30], tumor lysis syndrome [31], and neutropenia with an absolute neutrophil count less than $1,000 / \mathrm{mm}^{3}$ have all been implicated as risk factors for NEC with subsequent bowel perforation [32]. Prior episodes of neutropenic enterocolitis also appear to increase the risk of chemotherapy-induced NEC [33].

Endoscopy is relatively contraindicated in NEC; yet histological examination remains the gold standard for its diagnosis. Endoscopic characteristics of NEC, obtained via colonoscopy or sigmoidoscopy, include mucosal ulceration, edema, erosions, erythema, pseudomembrane, nodularity, friability, and loss of vascular pattern [13]. Conservative treatment with antibiotics, bland diet, hydration, and an effective pain treatment is favored for the treatment of neutropenic enterocolitis [34], whereas surgical intervention is necessary in cases of fulminant colitis and perforation [35].

Another proposed mechanism for bowel injury due to paclitaxel is its direct effect on the gastrointestinal mucosa without observable neutropenia [1]. It is said to arrest cellular division and promote intestinal cell death, which eventually leads to perforation. This was suggested by Hruban et al. [32], who showed the presence of gastrointestinal mitotic arrest in autopsy-derived specimens of the esophagus, stomach, small intestine, colon, liver, skin, bone marrow, and testes following paclitaxel treatment.

Bowel perforation associated with chemotherapeutic agents is an uncommon presentation, but one with a high mortality rate of $48 \%$ when treated medically and of $21 \%$ when treated surgically [36]. The incidence of paclitaxel-induced intestinal perforation is reported as $2.5 \%$ and is associated with a high mortality rate of $57 \%$ [30]. Only a handful of cases have been described in the literature. Seewaldt et al. [37] reported gastrointestinal necrosis with an incidence of $2.3 \%$ amongst patients treated with paclitaxel for ovarian cancer. Rose and Piver [18] alluded to colonic perforation in 3 patients undergoing paclitaxel-based chemotherapy.

\section{Karger'=}




\section{Case Reports in Gastroenterology}

\begin{tabular}{l|l}
\hline Case Rep Gastroenterol 2020;14:687-694 \\
\hline DOI: 10.1159/000510131 & $\begin{array}{l}\text { @ 2020 The Author(s). Published by S. Karger AG, Basel } \\
\text { www.karger.com/crg }\end{array}$ \\
\hline
\end{tabular}

Patients with bowel perforation can be asymptomatic or present with severe abdominal pain with hemodynamic instability. An upright radiograph can detect free intraperitoneal air under the diaphragm. CT scanning is the imaging modality of choice to detect the free air and the site of perforation [38]. Immediate hemodynamic resuscitation should be initiated with intravenous fluids and prophylactic antibiotics, and prompt surgical consultation should be obtained.

\section{Statement of Ethics}

The patient provided written informed consent (including the publication of images).

\section{Conflict of Interest Statement}

The authors declare no conflicts of interest.

\section{Funding Sources}

No funding was received.

\section{Author Contributions}

D.H. Shaikh and A. Baiomi searched the literature and wrote and revised the manuscript. H. Abbas, S. Mehershahi, and S. Gongati edited and revised the manuscript. S.K. Nayudu revised and approved the final version, and is the article's guarantor. All authors certify that they contributed sufficiently to the intellectual content and data analysis. Each author has reviewed the final version of the manuscript and approves it for publication.

\section{Data Availability Statement} duce it.

Should the editors request the data upon which the work is based, the authors shall pro-

\section{References}

1 Boussios S, Pentheroudakis G, Katsanos K, Pavlidis N. Systemic treatment-induced gastrointestinal toxicity: incidence, clinical presentation and management. Ann Gastroenterol. 2012;25(2):106-18.

2 Davila M, Bresalier RS. Gastrointestinal complications of oncologic therapy. Nat Clin Pract Gastroenterol Hepatol. 2008 Dec;5(12):682-96.

3 Montoya JE, Luna HG, Morelos AB, Catedral MM, Lava AL, Amparo JR, et al. Association of creatinine clearance with neutropenia in breast cancer patients undergoing chemotherapy with fluorouracil, doxorubicin, and cyclophosphamide (FAC). Med J Malaysia. 2013 Apr;68(2):153-6.

\section{Karger'"}




\section{Case Reports in Gastroenterology}

4 Ibrahim NK, Sahin AA, Dubrow RA, Lynch PM, Boehnke-Michaud L, Valero V, et al. Colitis associated with docetaxel-based chemotherapy in patients with metastatic breast cancer. Lancet. 2000 Jan;355(9200): 281-3.

5 D'Amato G, Rocha Lima C, Mahany JJ, Muro-Cacho C, Haura EB. Neutropenic enterocolitis (typhilitis) associated with docetaxel therapy in a patient with non-small-cell lung cancer: case report and review of literature. Lung Cancer. 2004 Jun;44(3):381-90.

6 Stojanovska V, Sakkal S, Nurgali K. Platinum-based chemotherapy: gastrointestinal immunomodulation and enteric nervous system toxicity. Am J Physiol Gastrointest Liver Physiol. 2015 Feb;308(4):G223-32.

7 Lee CS, Ryan EJ, Doherty GA. Gastro-intestinal toxicity of chemotherapeutics in colorectal cancer: the role of inflammation. World J Gastroenterol. 2014 Apr;20(14):3751-61.

8 Milles SS, Muggia AL, Spiro HM. Colonic Histologic Changes Induced by 5-Fluorouracil. Gastroenterology. 1962;43(4):391-9.

9 Osterlund P, Ruotsalainen T, Peuhkuri K, Korpela R, Ollus A, Ikonen M, et al. Lactose intolerance associated with adjuvant 5-fluorouracil-based chemotherapy for colorectal cancer. Clin Gastroenterol Hepatol. 2004 Aug;2(8):696-703.

10 Ropert S, Vignaux O, Mir O, Goldwasser F. VEGF pathway inhibition by anticancer agent sunitinib and susceptibility to atherosclerosis plaque disruption. Invest New Drugs. 2011 Dec;29(6):1497-9.

11 Jayakody S, Wright DB, Chiong C, Liu M, Bouffler C, El-Khoury T. Rectal perforation following paclitaxel and carboplatin chemotherapy for advanced ovarian cancer: a case report and review of the literature. J Med Case Reports. 2018 Aug;12(1):221.

12 Soularue E, Lepage P, Colombel JF, Coutzac C, Faleck D, Marthey L, et al. Enterocolitis due to immune checkpoint inhibitors: a systematic review. Gut. 2018 Nov;67(11):2056-67.

13 Xia R, Zhang X. Neutropenic enterocolitis: a clinico-pathological review. World J Gastrointest Pathophysiol. 2019 Oct;10(3):36-41.

14 Nesher L, Rolston KV. Neutropenic enterocolitis, a growing concern in the era of widespread use of aggressive chemotherapy. Clin Infect Dis. 2013 Mar;56(5):711-7.

15 Mukhtar E, Adhami VM, Mukhtar H. Targeting microtubules by natural agents for cancer therapy. Mol Cancer Ther. 2014 Feb;13(2):275-84.

16 Liu ZC, Wu D, Lan SJ, Wang DD. A case of multiple intestinal perforation secondary to paclitaxel and carboplatin combined chemotherapy for lung cancer [in Chinese]. Zhonghua Zhong Liu Za Zhi. 2019 May;41(5):399-400.

17 Mandai K, Shirakawa A, Uno K, Yasuda K. Endoscopic Ultrasound-Guided Drainage of Intra-Abdominal Abscess after Gastric Perforation in a Patient Receiving Ramucirumab and Paclitaxel for Advanced Gastric Cancer. Case Rep Oncol. 2017 Jan;10(1):15-20.

18 Rose PG, Piver MS. Intestinal perforation secondary to paclitaxel. Gynecol Oncol. 1995 May;57(2):270-2.

19 Samejima J, Adachi H, Kawamoto M, Saeki H, Kato N, Fujisawa J, et al. Rectal perforation in a patient treated with combination chemotherapy for lung cancer [in Japanese]. Gan To Kagaku Ryoho. 2009 Feb;36(2): 301-4.

20 Chen E, Abu-Sbeih H, Thirumurthi S, Mallepally N, Khurana S, Wei D, et al. Clinical characteristics of colitis induced by taxane-based chemotherapy. Ann Gastroenterol. 2020 Jan-Feb;33(1):59-67.

21 Guchelaar HJ, ten Napel CH, de Vries EG, Mulder NH. Clinical, toxicological and pharmaceutical aspects of the antineoplastic drug taxol: a review. Clin Oncol (R Coll Radiol). 1994;6(1):40-8.

22 Zhou X, Hu P, Yue Y, Duan Z. A case of occult bowel perforation after a cycle of chemotherapy for advanced epithelial ovarian carcinoma. Eur J Gynaecol Oncol. 2012;33(5):540-2.

23 Seewaldt V, Cain JM, Greer BE, Tamimi H, Figge DC. Bowel complications with taxol therapy. J Clin Oncol. 1993 Jun;11(6):1198.

24 Schorge JO. Laparoscopic diverting loop ileostomy for spontaneous colon perforation in advanced ovarian cancer. Gynecol Oncol Rep. 2019 Mar;28:84-5.

25 Mendivil AA, Micha JP, Brown JV 3rd, Rettenmaier MA, Abaid LN, Lopez KL, et al. Increased incidence of severe gastrointestinal events with first-line paclitaxel, carboplatin, and vorinostat chemotherapy for advanced-stage epithelial ovarian, primary peritoneal, and fallopian tube cancer. Int J Gynecol Cancer. 2013 Mar;23(3):533-9.

26 Wade DS, Nava HR, Douglass HO Jr. Neutropenic enterocolitis. Clinical diagnosis and treatment. Cancer. 1992 Jan;69(1):17-23.

27 Rodrigues FG, Dasilva G, Wexner SD. Neutropenic enterocolitis. World J Gastroenterol. 2017 Jan;23(1):42-7.

28 Davila ML. Neutropenic enterocolitis. Curr Opin Gastroenterol. 2006 Jan;22(1):44-7.

29 Rolston KV, Bodey GP, Safdar A. Polymicrobial infection in patients with cancer: an underappreciated and underreported entity. Clin Infect Dis. 2007 Jul;45(2):228-33.

30 de Haan D, van den Berg M. Colonic perforation secondary to taxol therapy: an unusual presentation. Onkologie. 2006 Nov;29(11):541-2. 


\section{Case Reports in Gastroenterology}

\begin{tabular}{l|l}
\hline Case Rep Gastroenterol 2020;14:687-694 \\
\hline DOI: 10.1159/000510131 & $\begin{array}{l}\text { @ 2020 The Author(s). Published by S. Karger AG, Basel } \\
\text { www.karger.com/crg }\end{array}$ \\
\hline
\end{tabular}

Shaikh et al.: Paclitaxel-Induced Bowel Perforation

31 Carter J, Durfee J. A case of bowel perforation after neoadjuvant chemotherapy for advanced epithelial ovarian cancer. Gynecol Oncol. 2007 Dec;107(3):586-9.

32 Hruban RH, Yardley JH, Donehower RC, Boitnott JK. Taxol toxicity. Epithelial necrosis in the gastrointestinal tract associated with polymerized microtubule accumulation and mitotic arrest. Cancer. 1989 May;63(10):1944-50.

33 Keidan RD, Fanning J, Gatenby RA, Weese JL. Recurrent typhlitis. A disease resulting from aggressive chemotherapy. Dis Colon Rectum. 1989 Mar;32(3):206-9.

34 O'Connor K, Dijkstra B, Kelly L, McDermott EW, Hill AD, O'Higgins N. Successful conservative management of neutropenic enterocolitis: a report of two cases and review of the literature. ANZ J Surg. 2003 Jun;73(6):463-5.

35 Radulović S, Golubović Z, Jovanović B, Pejanović J. Surgery for neutropenic enterocolitis, a complication in acute lymphoblastic leukemia [in Serbian]. Srp Arh Celok Lek. 2004 Oct;132 Suppl 1:119-21.

36 Ettinghausen SE. Collagenous colitis, eosinophilic colitis, and neutropenic colitis. Surg Clin North Am. 1993 Oct;73(5):993-1016

37 Seewaldt VL, Cain JM, Goff BA, Tamimi H, Greer B, Figge D. A retrospective review of paclitaxel-associated gastrointestinal necrosis in patients with epithelial ovarian cancer. Gynecol Oncol. 1997 Nov;67(2):137-40.

38 Torrisi JM, Schwartz LH, Gollub MJ, Ginsberg MS, Bosl GJ, Hricak H. CT findings of chemotherapy-induced toxicity: what radiologists need to know about the clinical and radiologic manifestations of chemotherapy toxicity. Radiology. 2011 Jan;258(1):41-56.

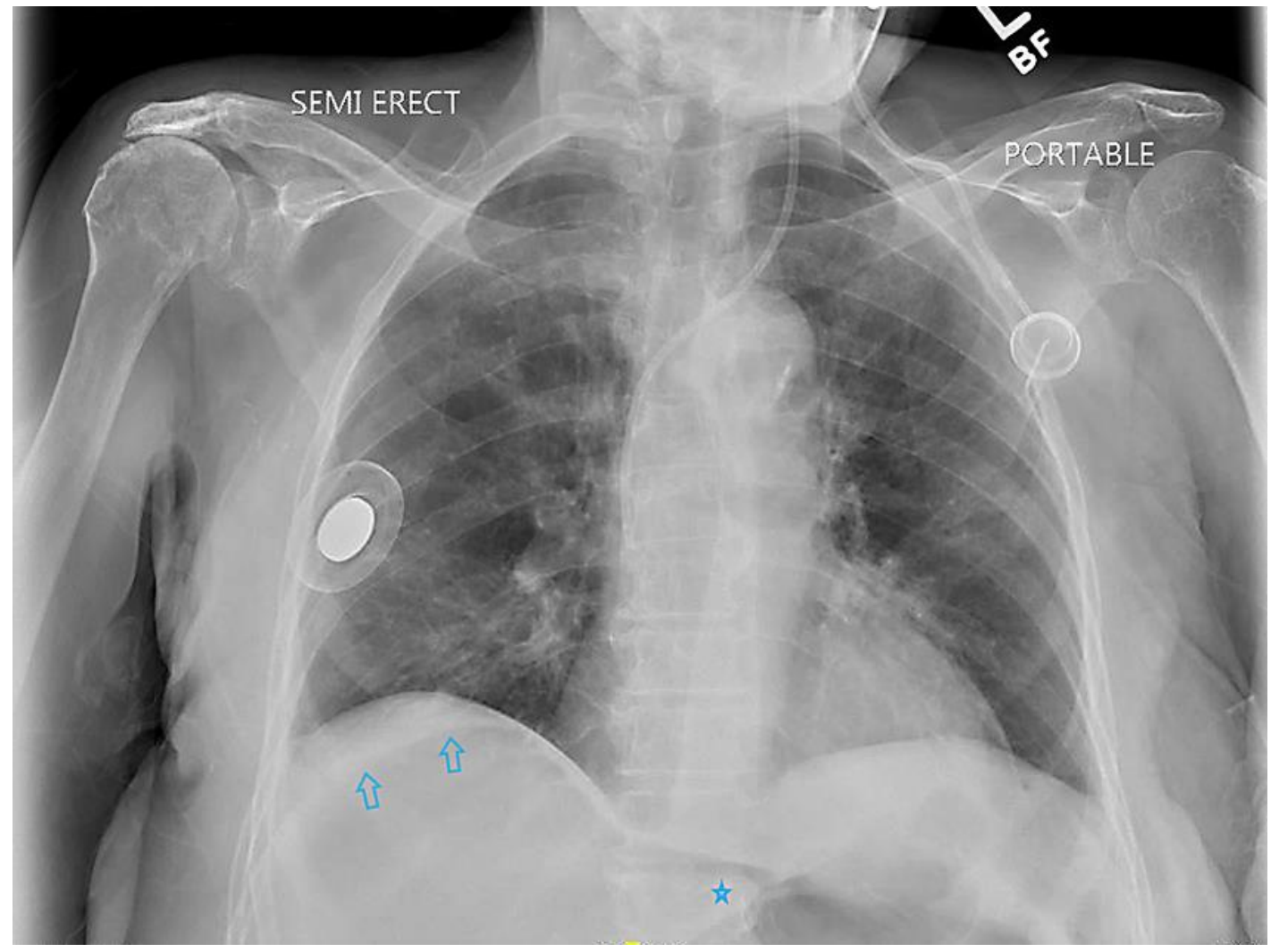

Fig. 1. Chest X-ray demonstrating subdiaphragmatic areas of lucency over the right upper quadrant (arrows), with apparent outlining of the left hepatic margin (asterisk) concerning for free intraperitoneal gas. 


\section{Case Reports in Gastroenterology}
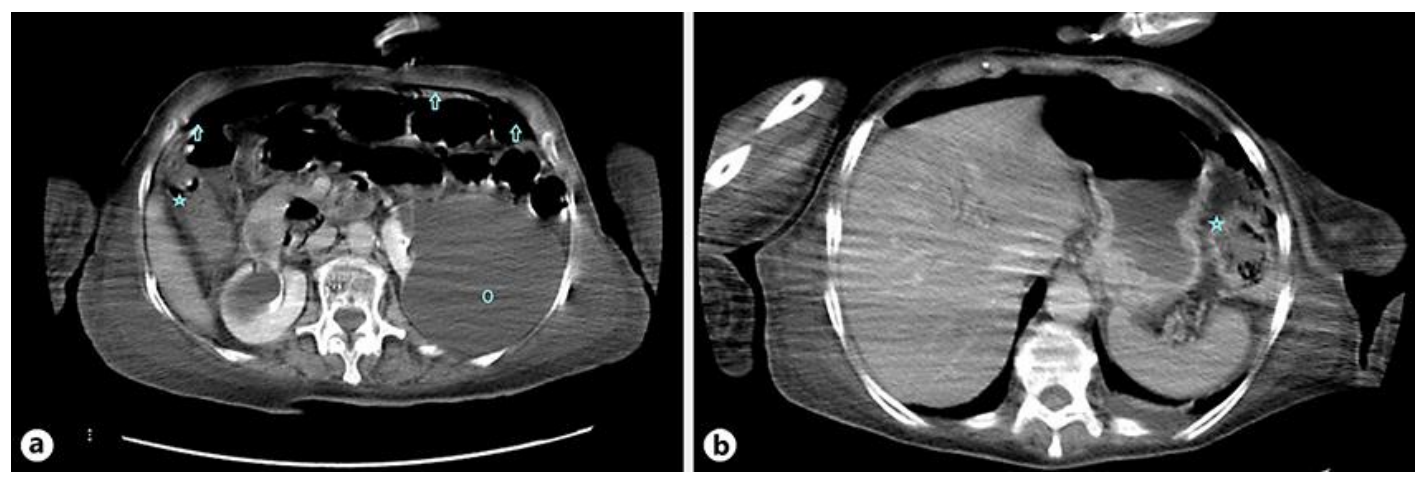

Fig. 2. a CT of the abdomen and pelvis without contrast demonstrating free intraperitoneal air (arrows) and an abnormal right colonic morphology with thickening in the region of the hepatic flexure (asterisk), possibly the site of the perforation with adjacent free fluid. Also seen is a large left renal cyst (circle). b CT of the abdomen and pelvis without contrast demonstrating a large air-fluid level in the left mid-abdomen between bowel loops (asterisk). This may also be a site of perforation with a loculated collection. It is surrounded by small bowel loops anteriorly, and the colon along its posterior margin, from which it appears inseparable. 